\title{
Branchio-oculo-facial syndrome
}

INSERM

\section{Source}

INSERM. (1999). Orphanet: an online rare disease and orphan drug data base. Branchiooculo-facial syndrome. ORPHA:1297

Branchio-oculo-facial syndrome (BOFS) is characterised by low birth weight and growth retardation, bilateral branchial clefts that may be hemangiomatous, sometimes with linear skin lesions behind the ears ('burn-like' lesions), congenital strabismus, obstructed nasolacrimal ducts, a broad nasal bridge with a flattened nasal tip, a protruding upper lip with an unusually broad and prominent philtrum, and full mouth. 